\title{
Osteoarticular complications of brucellosis: The diagnostic value and importance of detection matrix metalloproteinases
}

\author{
Maida Šiširak ${ }^{1^{*}}$, Mirsada Hukić \\ ${ }^{1}$ Institute for Clinical Microbiology \\ Clinical Centre University of Sarajevo \\ Bosnia and Herzegovina ${ }^{2}$ Academy \\ of Sciences and Arts of Bosnia and \\ Herzegovina
}

\footnotetext{
${ }^{*}$ Corresponding author: maidasisirak@yahoo.com

Tel.: + 38733298291

Fax.: + 38733226960
}

Received: 9 September 2014 Accepted: 8 December 2014

Key words: Brucellosis - Matrix metalloproteinase - Osteoarticular complications

\begin{abstract}
Objectives. Matrix metalloproteinases (MMPs) has been implicated in the pathogenesis of infective, cancer and autoimmune diseases. In this study, we investigated the serum level of MMPs and its clinical importance in human brucellosis. Patients and methods. This study included 60 brucellosis patients treated at the Clinic for Infectious Diseases, Clinical Centre, University of Sarajevo. Matrix metalloproteinases serum levels were quantified by ELISA. Results. The investigation involved three groups: 30 patients with complications, 30 patients without complications of brucellosis and 30 healthy control examinees. The complications of human brucellosis varied but osteoarticular involvement dominated $(n=21 / 30 ; 70 \%)$. Matrix metalloproteinases serum levels in the patients with complications were highest. The serum level of MMP-1 in patients with complications was the highest at 9.45; in patients without complications it was 3.78 and in the control examinees it was lowest at $3.62(\mathrm{p}=0.001)$. The serum level of MMP-9 in patients with complications was the highest at 105.66; in patients without complications 64.67 , and in the control examinees it was lowest at $37.32(\mathrm{p}=0.001)$. The serum level of MMP-13 in patients with complications was highest at 138.86 ; in patients without complications at 64.85; and in the control examinees it was the lowest at 29.55 $(\mathrm{p}=0.001)$. Pearson's coefficient showed a statistically significant positive correlation between levels of tested matrix metalloproteinases and development complications in human brucellosis $(\mathrm{p}=0.001)$. Conclusion. This study showed the diagnostic value and importance of detection of matrix metalloproteinases in human brucellosis. MMPs are a useful serum biomarker for assessment of disease activity
\end{abstract}

\section{Introduction}

Brucellosis is an important public health problem throughout the world, particularly in the Mediterranean region, the Arabian Peninsula, the Indian subcontinent, and parts of Central and South America $(1,2)$. Brucellosis is primarily an animal disease, and in them it passes as an asymptomatic chronic infection. Infections of humans follow the spread of brucellosis in animals. Clinical findings in brucellosis are non-specific, such as fever, sweat, malaise, anorexia, headache and back pain $(1,2)$. Diagnosis of brucellosis is on the basis of the clinical picture, epidemiological and anamnestic data and laboratory analysis. Early diagnosis of brucellosis, including adequate antibiotic therapy, has crucial importance for patients, especially for protection from development of complications. 
Complications of human brucellosis were registered in $10 \%-16 \%$ patients and osteoarticular involvement dominated $(2,3)$. The three most common forms of osteoarticular involvement are sacroilitis, spondylodiscitis and peripheral arthritis (3). Loss of bone is a serious complication of localized bacterial infection of the bones or the adjacent tissue. Despite the fact that clinical and imaging aspects of osteoarticular brucellosis have been described widely, the mechanisms involved in this process have not been completely explained (3). The skeleton is a dynamic organ system which is constantly being remodelled. These processes involve the coordinated effort of osteoblasts and osteoclasts (4). Together, these cell functions ensure healthy bones, giving strength and rigidity to the skeletal system. Osteoblasts are responsible for the deposition of the bone matrix and are thought to facilitate its calcification and mineralization. In contrast, osteoclasts drive the resorption of bone by acidification and the release of lysosomal enzymes, and these cells also produce bone resorption the secretion of MMP-9 $(4,5)$. Recent studies have explained that Brucella spp. can infect and survive within human osteoblasts and that this infection elicits the secretion of proinflammatory cytokines, chemokines and matrix metalloproteinases, that might be involved in the development osteoarticular complications of brucellosis $(6,7)$.

Matrix metalloproteinases (MMPs) has been implicated in the pathogenesis of infective, cancer and autoimmune diseases. MMPs represent a family of matrix-degrading proteinases with structural similarities. They require coordination of zinc ions at the active site for catalysis. Activity of matrix metalloproteinases is specifically inhibited by the tissue inhibitors of matrix metalloproteinases (TIMPs). To date 20 MMPs have been identified. They can be loosely subdivided on the basis of their substrate specificity into collagenases, gelatinases, strome- lysins, matrilysin, macrophage elastase, and four membrane-type MMPs (MT-MMPs). MMP production and activity are highly regulated. Normal tissues do not store MMPs, and constitutive expression is minimal. MMPs are transcriptionally regulated by growth factors, cytokines, and extracellular matrix (ECM) components (8-10). Since MMPs have the capacity to catalyze the degradation of structural ECM proteins, it has been tempting to speculate that their main role is physiological tissue remodelling during development, growth, uterine cycling, postpartum involutio, and wound repair (10). Exuberant expression of MMPs can cause tissue damage, and has been associated with a variety of destructive diseases, including atherosclerotic plaque rupture, aortic aneurysms, tumour progression and arthritis (10). Focus on this family of proteases is particularly emphasized in two major arthritis in humans, osteoarthritis and rheumatoid arthritis $(11,12)$. Although these forms of arthritis are different in terms of origin, they share the destruction mechanisms of the articular cartilage by proteinases. In human osteoarthritis, many MMPs are expressed in articular cartilage. The immunohistochemical expression levels of MMPs in chondrocytes are reported to correlate directly with the histological destruction score of the articular cartilage (12).

The present study deals with the usefulness and importance of detection matrix metalloproteinases in the diagnosis of human brucellosis.

\section{Materials and methods}

\section{Patient data}

This study included 60 brucellosis patients and 30 control examinees. The patients were divided into two subgroups: 30 patients with complications and 30 patients without complications of brucellosis. The average age of 
patients was $49.9 \pm 14.2$ years (range 15-81). Among the patients there were 39 (66\%) males and 21 (34\%) females. All patients were treated at the Clinic for Infectious Diseases, Clinical Centre University of Sarajevo. The average age of the control group of examinees was $36 \pm 52.5$ years of life, ranging from 18 to 55 . There were $26(86.6 \%)$ males and $4(13.4 \%)$ females. All laboratory testing for brucellosis was performed at the Institute for Clinical Microbiology of the Institute for Immunology, Clinical Centre University of Sarajevo. The criterion for inclusion in the study was the etiological confirmation of diagnosis by the relevant laboratory tests. Criteria for exclusion were other inflammatory diseases, autoimmune and malignant diseases. The disease was diagnosed by positive blood culture results and/or by positive relevant serological test results (ELISA, Rose-Bengal latex agglutination). The medical histories of 60 brucellosis patients were analysed. Patient data demonstrated that in order to assess morphological changes in the osteoarticular system, conventional radiological methods had been used (standard radiography-X-ray, computerized tomography-CT and magnetic resonance imagingMRI).

\section{Serological tests}

For serology, blood samples of patients were examined on the first day of hospitalization at the Clinic for Infectious Diseases, Clinical Centre University of Sarajevo. Blood samples were centrifuged and serum was stored in refrigerators at $-80^{\circ} \mathrm{C}$ until needed. Serum was evaluated using the RoseBengal test and ELISA (IgM and IgG). The Rose-Bengal latex agglutination test was performed according to the standard procedures. Undiluted serum samples $(30 \mu \mathrm{L})$ were mixed with an equal volume of Rose Bengal slide screening test antigen (bio Merioux, Marcy L Etoile/France). The results were rated negative when agglutination was absent and $1+$ to $4+$ positive according to the strength of the agglutination. Brucella IgM and IgG enzyme-linked immunosorbent assays (ELISAs) were performed and evaluated according to the kit procedure (Genzyme Virotech GmbH, Germany). The test results were read automatically by a BEP 2000-Behring ELISA processor.

Matrix metalloproteinases serum levels were quantified by sandwich ELISA (enzyme-linked immunosorbent assay) using paired MMP-specific monoclonal antibodies, according to the manufacturer's instructions (R\&D Systems, Inc., Minneapolis, USA). The test results were read automatically by a BIOTEK ELX50 ELISA processor on $450 / 620 \mathrm{~nm}$. We converted receiving values into $\mathrm{pg} / \mathrm{ml}$ using the program MASTERPLEX 2010.

\section{Statistical analysis}

For evaluation of the results, standard statistical methods were used. An analysis of the normality of the continuous variables was performed with the Kolmogorov-Smirnov test. The test showed that all variables satisfied the characteristics of normal distribution. A comparison of the categorical and continuous variables between the groups was performed using the chi-square test and one-way variance analysis (ANOVA). Correlation between investigated variable was found using Pearson's coefficient linear correlation. Statistical significance was defined at $\mathrm{p}<0.05$. Statistical analysis was performed using the statistical package IBM Statistics SPSS V19.0.

\section{Ethical principles}

The ethical principles outlined in the World Medical Association Helsinki Declaration were applied in this study. 


\section{Results}

The investigation involved three groups: 30 patients with complications, 30 patients without complications of brucellosis and 30 in a control group of healthy examinees. $\mathrm{Pa}$ tients had different forms of brucellar complications. Osteoarticular complications were dominant ( $\mathrm{n}=21 / 30 ; 70 \%)$. The most common form of osteoarticular complication was peripheral arthritis $(\mathrm{n}=10 / 21 ; 47.61 \%)$, followed by spondylodiscitis $(\mathrm{n}=9 / 21 ; 42.85 \%)$ and sacroilitis $(n=4 / 21 ; 19.04 \%)$. Some patients had manifestations on two segments of the bone-joint system (Figure 1).

The time between onset of symptoms and diagnosis of osteoarticular complications was 7.6 \pm 5.4 weeks. The length of diagnostic time was different for different forms of osteoarticular complications. We detected a correlation between the length of diagnostic time and different forms of osteoarticular complications. Nearly twice the length of time was necessary to define the diagnosis of spondylodiscitis (113 days) in relation to arthritis (56 days) and sacroilitis (64 days).

Analysis of the serum level of MMP-1, revealed that in patients with complications it was the highest at 9.45; in patients without complications it was 3.78 and in the control examinees it was the lowest at 3.62 , with statistically significant differences between the groups ( $\mathrm{p}=0.001)$ (Table 1). Serum levels of MMP-9 in patients with complications were the highest at 105.66; in patients without complications they were at 64.67 , and in the control examinees they were the lowest at 37.32 , with statistically significant differences between the groups $(\mathrm{p}=0.001)$ (Table 2$)$. The serum level of MMP-13 in patients with complications was the highest at 138.86; in patients without complications it was 64.85 ; and in the control examinees it was the lowest at 29.55 , with statistically significant differences between the groups ( $\mathrm{p}=0.001$ ) (Table 3). Pearson's coefficient of correlation showed a statistically significant positive correlation between levels of tested matrix metalloproteinases and the development of complications in human brucellosis $(\mathrm{p}=0.001)$.

We analysed the correlation between the length of diagnostic time and serum levels of MMPs (MMP-1, MMP-9, MMP-13). MMP-9 and especially MMP-13 showed a correlation with the length of diagnostic time (Figure 2).

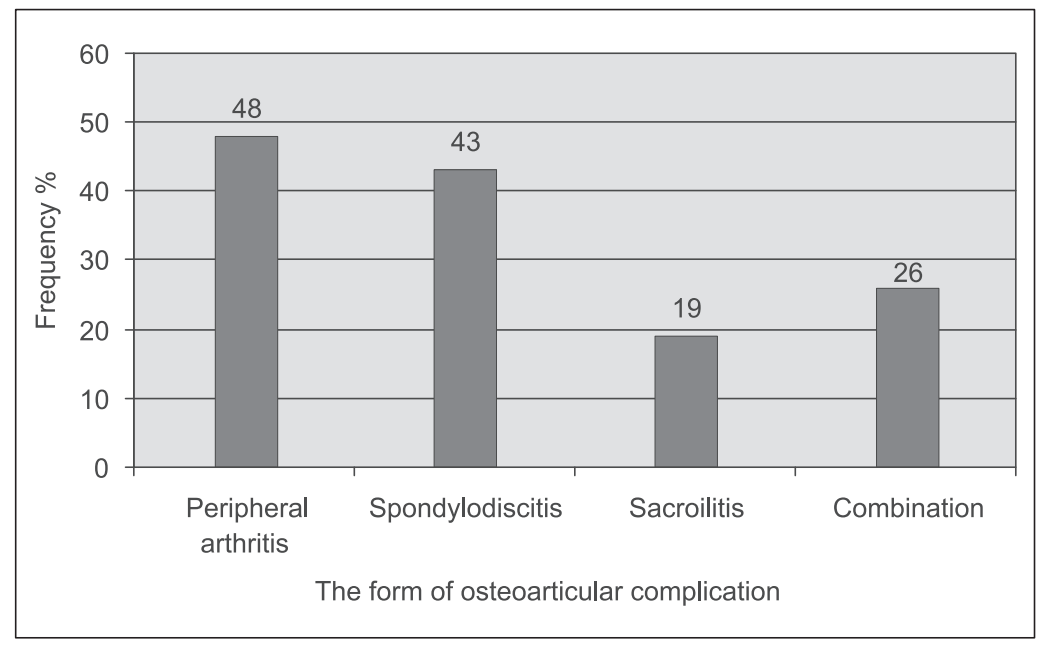

Figure 1 The most common forms of osteoarticular complications in brucellosis. 
Table 1 Evaluation of serum level of MMP-1 (pg/ml)

\begin{tabular}{llllll}
\hline \multirow{2}{*}{ Groups } & \multicolumn{5}{l}{ Serum level of Matrix metalloproteinase1 $(\mathrm{pg} / \mathrm{ml})$} \\
\cline { 2 - 6 } & AS & SD & SEM & Min. & Max. \\
\hline Patients with complications $(\mathrm{n}=30)$ & 9.45 & 8.16 & 1.49 & 1.14 & 40.96 \\
Patients without complications $(\mathrm{n}=30)$ & 3.78 & 2.57 & 0.47 & 0.48 & 8.70 \\
Control $(\mathrm{n}=30)$ & 3.62 & 3.11 & 0.57 & 0.50 & 14.07 \\
\hline
\end{tabular}

$\mathrm{F}=11.964$ (results of ANOVA), $\mathrm{p}=0.001 ; \mathrm{AS}=$ Arithmetic mean; $\mathrm{SD}=$ Standard deviation; $\mathrm{SEM}=\mathrm{Standard}$ error of the mean; Min=Minimum; Max=Maximum.

Table 2 Evaluation of serum level of MMP-9 $(\mathrm{pg} / \mathrm{ml})$

\begin{tabular}{llllll}
\hline \multirow{2}{*}{ Groups } & \multicolumn{5}{l}{ Serum level of Matrix metalloproteinase9 $(\mathrm{pg} / \mathrm{ml})$} \\
\cline { 2 - 6 } & AS & SD & SEM & Min. & Max. \\
\hline Patients with complications $(\mathrm{n}=30)$ & 105.66 & 46.93 & 8.57 & 11.24 & 196.34 \\
Patients without complications $(\mathrm{n}=30)$ & 64.67 & 25.66 & 4.68 & 19.64 & 112.89 \\
Control $(\mathrm{n}=30)$ & 37.32 & 0.99 & 0.18 & 35.57 & 38.77 \\
\hline
\end{tabular}

$\mathrm{F}=37.233$ (results of ANOVA), $\mathrm{p}=0.001 ; \mathrm{AS}=$ Arithmetic mean; $\mathrm{SD}=$ Standard deviation; $\mathrm{SEM}=$ Standard error of the mean; Min=Minimum; Max=Maximum.

Table 3 Evaluation of serum level of MMP-13 $(\mathrm{pg} / \mathrm{ml})$

\begin{tabular}{llllll}
\hline \multirow{2}{*}{ Groups } & \multicolumn{5}{l}{ Serum level of Matrix metalloproteinase13 $(\mathrm{pg} / \mathrm{ml})$} \\
\cline { 2 - 6 } & AS & SD & SEM & Min. & Max. \\
\hline Patients with complications $(\mathrm{n}=30)$ & 138.86 & 97.99 & 17.89 & 47.99 & 576.92 \\
Patients without complications $(\mathrm{n}=30)$ & 64.85 & 36.74 & 6.71 & 29.06 & 183.51 \\
Control $(\mathrm{n}=30)$ & 29.55 & 0.00 & 0.00 & 29.56 & 29.56 \\
\hline
\end{tabular}

$\mathrm{F}=25.572$ (results of ANOVA), $\mathrm{p}=0.001 ; \mathrm{AS}=$ Arithmetic mean; $\mathrm{SD}=\mathrm{Standard}$ deviation; $\mathrm{SEM}=\mathrm{Standard}$ error of the mean; Min=Minimum; Max=Maximum.

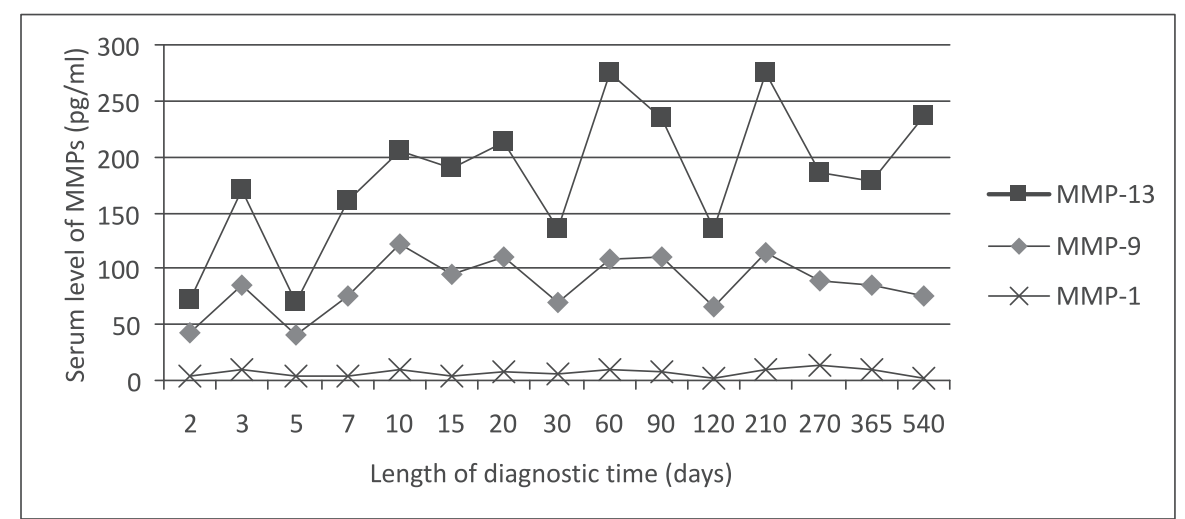

Figure 2 Correlation between the length of diagnostic time and serum level of MMPs.

\section{Discussion}

Brucellosis is a prevalent disease in humans and animals in our country. The clinical fea- tures and presentations of human brucellosis resemble various infectious, autoimmune or neoplastic processes. Diagnosis of brucellosis in this country without any ex- 
perience with this kind of infection, may be very difficult. Early diagnosis of brucellosis and adequate antibiotic therapy have crucial importance for patients, especially for protection from the development of complications. Osteoarticular complications are the most common, and present in the form of spondylodiscitis, sacroilitis, arthritis, tenosynovitis and osteomyelitis (3).

In the present study, osteoarticular complications were dominant $(n=21 / 30 ; 70 \%)$. The most common form of osteoarticular complication was peripheral arthritis, followed by spondylodiscitis and sacroilitis. We detected a correlation between the length of diagnostic time and different forms of osteoarticular complications. Nearly twice the length of time was necessary to define the diagnosis of spondylodiscitis in relation to arthritis and sacroilitis. Bosilkovski et al. (13) in a study in the Republic of Macedonia reported similar results, 59.2\% patients had osteoarticular complications. Recent studies in hospitals in various parts of the world have reported similar results (14-19).

The diagnosis of muscular and skeletal system involvement in brucellosis is based on the patient's history, combined with physical examination and imaging methods, of which radiography is the method used most widely. Radiography is the initial means of evaluation of osteoarticular involvement, although its lack of sensitivity in the early stages must be considered. In the early and acute stages, diagnosis of osteoarticular involvement can be difficult because radiography has limited capacity when no changes are present in the bones. Standard radiography showed a low level of sensitivity $(32.2 \%)$, particularly in the acute phase, due to its inability to differentiate inflammatory and degenerative changes (19). Other techniques that are used widely for imaging osteoarticular involvement are bone scanning, computerised tomography and magnetic resonance imaging (20-22). Bone scintigraphy has been shown as a sensitive method for detecting bone lesions of brucellosis throughout the body. However, its specificity is low (20). Moreover, bone scans do not detect soft tissue infection (20). This is a problem in diseases such as brucellosis, that have both osteoarticular and soft tissuerelated complications. Magnetic resonance imaging was a more sensitive method in brucellar osteoarticular changes $(21,22)$.

Recent studies have shown that brucellar arthritis is frequently destructive, with associated osteopenia and cartilage damage (13-19). However, the pathogenesis of development pathologic changes has not been explained.

Based on the results obtained in the present study, we hypothesize that matrix metalloproteinases may harm osteoblast function, contributing to bone and joint destruction observed in patients with brucellar osteoarticular complications. The results of our study revealed that serum levels of MMPs (MMP-1, MMP-9, MMP-13) in patients with complications were the highest; in patients without complications they were lower and in the control examinees the lowest, with statistically significant differences between the groups ( $p=0.001$ ). Pearson's coefficient of correlation showed a statistically significant positive correlation between levels of tested matrix metalloproteinases and development of complications in human brucellosis $(p=0.001)$. The expression of MMPs in the serum samples correlates with the parameters of arthritis activity, such as erythrocyte sedimentation rate and C-reactive protein. Also, their degree of expression in the serum samples correlates with the results of conventional radiological methods (standard radiography-X-ray, computerized tomography-CT and magnetic resonance imaging-MRI). Measurement the concentration of metalloproteinases in the serum is non-invasive, easy to perform, relatively inexpensive, and might be a promising 
procedure for evaluation of osteoarticular complications. Also, it might be a promising procedure for monitoring the efficiency of therapies in human brucellosis.

Results of our study showed that serum levels of MMP-13 dominated in all patients with osteoarticular complications. Takaishi H. et al. (12) in their study explained the role of MMP-13 in joint diseases. The study concluded that MMP-13 was expressed by chondrocytes and synovial cells in osteoarthritis and rheumatoid arthritis, and plays a critical role in cartilage destruction. MMP13 serum levels are useful for predicting joint destruction, and monitoring therapies.

The role of MMPs in immunopathogenesis infective and autoimmune osteoarticular diseases has been investigated over the last two decades $(17,18)$. In patients with inflammatory arthritis gelatinase (MMP-2, MMP-9) are expressed in the synovial membrane, and have been implicated in synovial tissue invasion into the adjacent cartilage and bone. It has been hypothesized that an imbalance between the activators and inhibitors of gelatinases results in higher levels of activity, enhanced local proteolysis, and bone erosion. Radiographic erosions are characteristic. Patients with radiographic erosions had significantly higher levels of active MMP-2 and MMP-9 $(17,18)$.

Although the clinical aspects of osteoarticular complications in human brucellosis have been described widely (13-19), their immunopathogenesis has been only partially described $(6,7)$. Wallach JC et al. (23) described a case of prepatellar bursitis in a man with chronic brucellosis. In this case report a high level of proinflammatory cytokines was detected in the synovial fluid. Also, by zymographic analysis the presence of MMP-9 was detected in the synovial fluid of a patient with bursitis. These findings suggest the role of increased local levels of proinflammatory cytokines and gelatinases in the inflammatory manifestations of bru- cellar bursitis. Delpino MV et al. (24) in an in vitro study, described the proinflammatory response of human osteoblast cell lines and osteoblast-monocyte interaction upon infection with Brucella spp. The study concluded that osteoblasts play an important role in the pathogenesis of osteoarticular complications in human brucellosis by production of MMPs (MMP-2, MMP-9) and proinflammatory cytokines.

To our knowledge, there are no reports on the ability of Brucella spp. to infect human osteoblasts, in vivo. This may be explained in part by ethical restrictions, since a biopsy of the affected bone may only be justified in very select cases. Studies, in vivo, are important to confirm many emerging and fascinating properties of MMPs.

The results of the present study point out the important role of matrix metalloproteinases in the development of osteoarticular brucellosis. This new knowledge contributes to a better understanding of the osteoarticular pathology of to human brucellosis.

A large number of different tests have been used for serological diagnosis of brucellosis, thus demonstrating the lack of an ideal technique. The Rose Bengal test is ideal for screening patients. ELISA is the method of choice for diagnosis of the chronic disease and relapses. Detection of matrix metalloproteinases in the serum is important for assessment of the disease activity and in predicting development of complications of brucellosis. The correlation between serum levels of MMPs and the results of conventional radiological methods shows the importance of detection of MMPs in the diagnostics of osteoarticular complications of brucellosis. Conventional radiological methods are not useful in determining the outcome of brucellar osteoarticular involvement, because abnormal uptake persists for a long period. Serum levels of MMPs decrease very quickly after adequate antibiotic 
therapy, thus demonstrating that they are a reliable technique for monitoring therapies.

\section{Conclusion}

This study clearly showed the diagnostic value and importance of detection of matrix metalloproteinases in human brucellosis. Measurement of the concentration of metalloproteinases in the serum is non-invasive, easy to perform, relatively fast, and might be a promising procedure for determining the outcome of brucellar osteoarticular involvement. Although increased levels of MMP-1, MMP-9 and MMP-13 are not specific and do not provide a definite clinical diagnosis, they can be used as a biochemical indicator of development of complications, when evaluated in combination with conventional radiological methods. Serum levels of MMPs decrease very quickly after adequate antibiotic therapy, thus demonstrating that they are a reliable technique for monitoring efficiency of therapies.

\section{What is already known on this topic}

- Matrix metalloproteinases has been implicated in the pathogenesis of infective, cancer and autoimmune diseases.

- MMPs production and activity are highly regulated.

- Normal tissues do not store MMPs, and constitutive expression is minimal.

- Exuberant expression of MMPs can cause tissue damage, and has been associated with a variety of destructive diseases, including atherosclerotic plaque rupture, aortic aneurysms, tumour progression and arthritis.

\section{What this study adds}

- This investigation showed the diagnostic value and importance of detection of matrix metalloproteinases in human brucellosis.

- Measurement of the concentration of metalloproteinases in the serum is non-invasive, easy to perform, relatively fast, and might be a promising procedure for determining the outcome of brucellar osteoarticular involvement.

- Serum levels of MMPs decrease very quickly after adequate antibiotic therapy, thus demonstrating that they are a reliable technique for monitoring the efficiency of therapies.
Authors' contributions: Conception and design: MŠ; Acquisition, analysis and interpretation of data: MŠ; Drafting the article: MŠ; Revising it critically for important intellectual content: $\mathrm{MH}$.

Conflict of interest: The authors declare that they have no conflict of interest.

\section{References}

1. Young EJ. An overview of human brucellosis. Clin Infect Dis. 1995;21:283-90.

2. Franco MP, Mulder M, Gilman RH, Smits HL. Human brucellosis. Lancet Infect Dis. 2007;7(12): 775-86.

3. Madkour MM. Osteoarticular brucellosis, In: Madkour MM, editor. Madkour's brucellosis. 2nd ed. Berlin: Springer-Verlag; 2001. p 74-87.

4. Hill PA. Bone remodeling. Br J Orthod. 1998;25: 101-7.

5. Delpino MV, Barrionuevo P, Macedo GC, Oliveira SC, Genaro SD, Scian R et al. Macrophage-elicited osteoclastogenesis in response to Brucella abortus infection requires TLR2/MyD88-dependent TNF- $\alpha$ production. J Leukoc Biol. 2012;91(2):28598.

6. Scian R, Barrionuevo P, Giambartolomei GH, Fossati CA, Baldi PC, Delpino MV. Granulocytemacrophage colony-stimulating factor- and tumor necrosis factoralpha-mediated matrix metalloproteinase production by human osteoblasts and monocytes after infection with Brucella abortus. Infect Immun. 2011;79(1):192-202.

7. Scian R, Barrionuevo P, Fossati CA, Giambartolomei GH, Delpino MV. Brucella abortus invasion of osteoblasts inhibits bone formation. Infect Immun. 2012;80(7):2333-45.

8. Nagase H, Woessner JF. Matrix metalloproteinases. J Biol Chem. 1999;274:2141-4.

9. Rosso F, Giordano A, Barbarisi M, Barbarisi A From cell-ECM interactions to tissue engineering. J Cell Physiol. 2004;199:174-80.

10. Stemlicht MD, Werb Z. How matrix metalloproteinases regulate cell behaviour. Annu Rev Cell Dev Biol. 2001;17:463-516.

11. Ahrens D, Koch AE, Pope RM, Stein-Picarella M, Niedbala MJ. Expression of Matrix metalloproteinase 9 (96-kd gelatinase B) in human rheumatoid arthritis. Arthrits Rheum. 1996;39:1576-87.

12. Takaishi H, Kimura T, Dalal S, Okada Y, D'Armiento J. Joint diseases and matrix metalloproteinases: a role for MMP-13. Curr Pharm Biotechnol. 2008;9(1):47-54. 
13. Bosilkovski M, Krateva Lj, Caparoska S, Dimzova M. Osteoarticular Involvement in Brucellosis: Study of 196 Cases in the Republic of Macedonia. Croat Med J. 2004;45(6):727-33.

14. Buzgan T, Karahocagil MK, Irmak H, Baran AI, Karsen H, Evirgen O, et al. Clinical manifestations and complications in 1028 cases of brucellosis: a retrospective evaluation and review of the literature. Int J Infect Dis. 2010;14:469-78.

15. Ertek M, Yazgi H, Kadanali A, Ozden K, Tasyaran MA. Complications of Brucella Infection among Adults: An 18-Year Retrospective Evaluation. Turk J Med Sci. 2006;36(6):377-81.

16. Hasanjani Roushan MR, Mohrez M, Smailnejad Gangi SM, Soleimani Amiri MJ, Hajiahmadi M. Epidemiological features and clinical manifestations in 469 adult patients with brucellosis in Babol, Northern Iran. Epidemiol Infect. 2004;132(6):1109-14.

17. Geyik MF, Gür A, Nas K, Cevik R, Saraç J, Dikici $\mathrm{B}$, et al. Musculoskeletal involvement in brucellosis in different age groups: a study of 195 cases. Swiss Med Wkly. 2002;132:98-105.

18. Solera J, Lozano E, Martinez-Alfaro E, Espinosa A, Castillejos ML, Abad L. Brucellar spondylitis: Review of 35 cases and literatura survey. Clin Infect Dis. 1999;29:1440-9.
19. Turgut M, Turgut AT, Kosar U. Spinal brucellosis: Turkish experience based on 452 cases published during the last century. Acta Neurochir (Wien). 2006;148:1033-44.

20. El-Desouki MI, Benjamin RS. Diagnostic value of quantitative sacroiliac joint scintigraphy in brucellosis. Clin Nucl Med. 1999;24:756-8.

21. Bollow M, Braun J, Hamm B, Eggens U, Schilling A, König H, et al. Early sacroiliitis in patients with spondyloarthropathy: evaluation with dynamic gadolinium-enhanced MR imaging. Radiology. 1995;194(2):529-36.

22. Blum U, Buitrago-Tellez C, Mundinger A, Krause T, Laubenberger J, Vaith P, et al. Magnetic resonance imaging (MRI) fordetection of active sacroileitis-a prospective study comparing conventional radiography, scintigraphy, and contrast enhanced MRI. J Rheumatol. 1996;23:2107-15.

23. Wallach JC, Delpino MV, Scian R, Deodato B, Fossati CA, Baldi PC. Prepatellar bursitis due to Brucella abortus: case report and analysis of the local immune response. J Med Microbiol. 2010;59 (Pt 12):1514-8.

24. Delpino MV, Fossati CA, Baldi PC. Proinflammatory response of human osteoblastic cell lines and osteoblast-monocyte interaction upon infection with Brucella spp. Infect Immun. 2009;77(3):98495. 